\title{
Proceeding
}

Supplementary Issue: Winter Conferences of Sports Science. Costa Blanca Sports Science Events, 22-23 March 2021. Alicante, Spain.

\section{Global postural evaluation and motor treatment in the subject with Down Syndrome: Clinical case reports}

\author{
GIUSEPPE DI FABRIZIO1 ${ }^{1}$, MARIA CHIARA PARISI ${ }^{1}$, CATERINA CRESCIMANNO ${ }^{1}$, FRANCESCA \\ OROFINO ${ }^{1}$, MARZIA FRATTALEMI², OMAR GAETANO MARIA MINGRINO1 \\ ${ }^{1}$ Faculty of Human and Social Sciences, University of Enna "Kore", Enna, Italy \\ ${ }^{2}$ Voluntary researcher graduated in Preventive and Adapted Motor Activity Sciences and Techniques, Enna, \\ Italy
}

\begin{abstract}
The aim of the study was to evaluate postural tonic changes and the motor difficulties of the subjects examined were taken into account. For the study, 10 subjects with Down syndrome between the ages of 17 and 38, 7 male and 3 females, were recruited, for a period of 10 month, all with different postural alterations and pathologies. Everyone three times a week performed adapted physical activity protocols; these have been customized and adapted to each individual case, taking into account not only the problems related to the syndrome, but also the emotional sphere of each of them and motor skills. The subjects were subjected a preliminary (TO) static and dynamic baropodometric tests and video-analysis and then repeated every three months (T1, T2). It's results total and partial improvements in $85 \%$ of cases. For each subject, an individual motor treatment program has been drawn up. We can conclude in saying that motor treatment is an important method of treating paramorphisms of the lower limb even in the case of subjects with Down Syndrome that translates into prevention and mitigation of the pathologies from which they suffer, improving daily life, autonomy and quality of life.

Keywords: Down Syndrome; Paramorphisms; Postural Exercise; Rehab; Motor Rehabilitation.

\section{Cite this article as:}

Di Fabrizio, G., Parisi, M.C., Crescimanno, C., Orofino, F., Frattalemi, M., \& Mingrino, O.G.M. (2021). Global postural evaluation and motor treatment in the subject with Down Syndrome: Clinical case reports. Journal of Human Sport and Exercise, 16(3proc), S938-S962. https://doi.org/10.14198/jhse.2021.16.Proc3.11
\end{abstract}

Corresponding author. Faculty of Human and Social Sciences, University of Enna "Kore", Enna, Italy.

E-mail: difa97@outlook.it

Abstract submitted to: Winter Conferences of Sports Science. Costa Blanca Sports Science Events, 22-23 March 2021. Alicante, Spain.

JOURNAL OF HUMAN SPORT \& EXERCISE ISSN 1988-5202.

(c) Faculty of Education. University of Alicante.

doi:10.14198/jhse.2021.16.Proc3.11 


\section{INTRODUCTION}

Down syndrome (DS), more properly trisomy 21 , is a genetic pathology caused by a supernumerary chromosome 21 in which phenotypic manifestations can result from the balance between genetic, environmental, and stochastic events (Reeves et al. 2001; Rachidi and Lopes 2007).

This predisposes more to pathologies of the CNS, gastrointestinal tract, visual apparatus, the cardiovascular system as well as posture disorders and therefore consequently to pathologies of the musculoskeletal system. (Roche et al. 2015).

Down syndrome is also associated with an increased incidence of autoimmune diseases, including thyroid disorders (Kennedy et al. 1992; Karlsson et al. 1998), with a well-documented increase in the risk and prevalence of type 1 diabetes (Anwar et al. 1998; Van Goor et al. 1997; Farquhar JW 1969; Gillespie et al. 2006).

Bertapelli et al. (2016), analysing 4280 studies on the subject, defines a combined prevalence of overweight and obesity in young people with DS ranging from $23 \%$ to $70 \%$ and a greater predisposition to overweight and obesity than subjects without DS.

At the expense of the musculoskeletal system, the subject with Down Syndrome has capsular ligament laxity and muscle hypotonia that can induce a delay in the acquisition of motor stages and lower levels of physical activity in children with DS. (Agiovlasitis et al. 2009; Jacobsen \& Hansson 2000; Caird et al. 2006; Chang et al. 2009).

Excessive joint excursion, caused by ligament laxity and muscle hypotonia, causes morphological changes in skeletal structures, which, in adulthood, can cause spontaneous fractures or dislocations. (Bennet et al. 1982; Hresko et al. 1993).

This is most evident in the lower limb where it is possible to detect, a valgism of the knees associated with pronation and flatness of the foot (about 58\%). (Volman et al. 2007; Perotti et al. 2018).

This system induces instability both in static and during walking that is bradykinetic, in small steps, and with an extension of the stance phase. (Cimolin et al. 2010; Galli et al. 2008).

The improvement of posture is now recognized as a method of prevention of pathologies at the expense of the musculoskeletal system and improvement of performance. (Francavilla et al. 2020; Parisi et al. 2001; Cristofalo et al. 1998).

Di Maio et al. (2020), Polito et al. (2020) Francavilla \& Francavilla (2013), agree that exercise can induce a reduction in oxidative stress, the incidence of cardiovascular diseases, complications related to diabetes, and the reduction of the incidence of metabolic disorders typical of obesity.

Other studies indicate that motor exercise, in this case, proprioceptive training and the selective muscle strengthening program, lead to benefits in terms of quality of life and prevention of musculoskeletal disorders in sportsmen. (Fischetti et al. 2020; Francavilla et al. 2003; Francavilla et al. 2016). 
Eid et al. (2017) showed that by subjecting subjects with DS to isokinetic training these developed better postural control and balance compared to the subjects in the control group.

\section{METHODOLOGY}

For the study, 10 subjects with Down syndrome between the ages of 17 and 38,7 male and 3 females, each with a flat foot, knee varus or valgus, pelvic dysmetria. They were recruited, for 10 months.

Sophisticated video analysis technologies and the latest generation baropodometric platform were used, for postural assessments. The "FreeStep" software, which is an advanced software for the study of baropodometry, posture, biomechanics, and the man-space relationship, and the "Sensor Medica" baropodometric platform were employed.

The people recruited were subjected to static and dynamic baropodometric tests and computerized videography, both in the initial phase (T0), in the intermediate phase of the study (T1), and after (T2) the treatments. The main parameters taken into account by baropodometry are plantar surface, pressure, force, load distribution.

Everyone three times a week performed adapted physical activity protocols; these have been customized and adapted to each case. The motor protocol included proprioceptive and coordination exercises to improve the quality of walking and to reduce awkwardness; stretching, balance, and muscle strengthening movements, to tone the muscles of the postural tonic system.

The purpose of the proprioceptive exercises was to stimulate the breech baroreceptors through complex but simple exercises to stimulate the pressoreceptors of the soles of the feet, which inform the brain about the current position and favour the correct functioning of the antigravity muscle chain.

Various types of tools were used for the motor treatments; more specific ones such as proprioceptive cushions and platforms, elastic bands, and dumbbells; but also, more common objects, used to achieve the purposes of the study. The choice was strategic because we tried, with success, to capture everyone's attention with different colours and shapes, proposing complex exercises in the form of games. For example, to restore walking coordination a "path of colours" was created which was struck by differentiating the plantar support.

Table 1. Sample data.

\begin{tabular}{lllll}
\hline & Age & Gender & Weight & Height \\
\hline First case & 31 & Male & $52.5 \mathrm{~kg}$ & $1.53 \mathrm{~m}$ \\
Second case & 29 & Male & $78.2 \mathrm{~kg}$ & $1.60 \mathrm{~m}$ \\
Third case & 20 & Male & $67.8 \mathrm{~kg}$ & $1.58 \mathrm{~m}$ \\
Fourth case & 17 & Male & $80.0 \mathrm{~kg}$ & $1.70 \mathrm{~m}$ \\
Fifth case & 21 & Male & $67.8 \mathrm{~kg}$ & $1.58 \mathrm{~m}$ \\
Sixth case & 35 & Male & $75.6 \mathrm{~kg}$ & $1.68 \mathrm{~m}$ \\
Seventh case & 38 & Male & $70.0 \mathrm{~kg}$ & $1.65 \mathrm{~m}$ \\
Eighth case & 22 & Female & $80.0 \mathrm{~kg}$ & $1.68 \mathrm{~m}$ \\
Nineth case & 35 & Female & $98.5 \mathrm{~kg}$ & $1.65 \mathrm{~m}$ \\
Tenth case & 17 & Female & $52.0 \mathrm{~kg}$ & $1.61 \mathrm{~m}$ \\
\hline
\end{tabular}


Table 2. Sample results.

\begin{tabular}{|l|l|}
\hline First case & Global improvements \\
\hline Second case & Global improvements \\
\hline Third case & Partial improvements \\
\hline Fourth case & Global improvements \\
\hline Fifth case & Partial improvements \\
\hline Sixth case & Global improvements \\
\hline Seventh case & Sample case \\
\hline Eighth case & Global improvements \\
\hline Nineth case & Sample case \\
\hline Tenth case & No improvement \\
\hline
\end{tabular}

\section{CLINICAL CASE REPORTS}

Below are reported the pre-and post-treatment global postural evaluation of 10 subjects with DS.

\section{First Clinical Case}

TO Evaluation

STATIC ANALYSIS

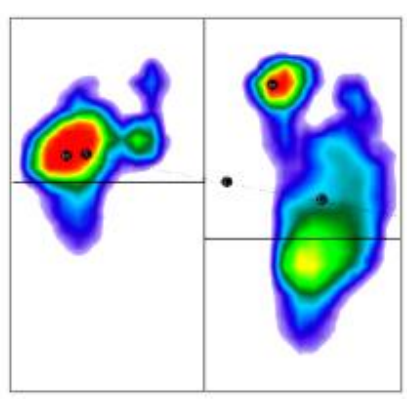

FRONT VIEW

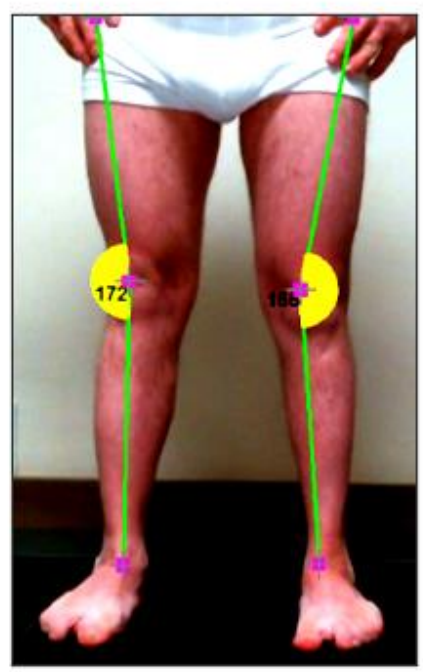

DYNAMIC ANALYSIS

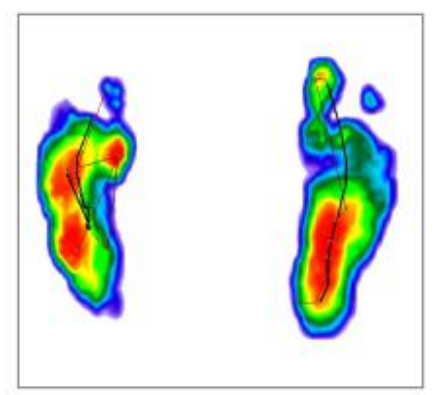

REAR VIEW

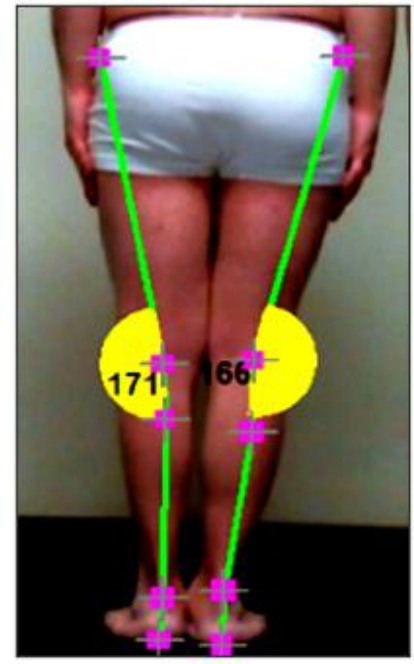

Figure 1. First Clinical Case T0. 
Case 1 presented irregular plantar support. From the static and dynamic examination, the body centre of gravity was off-centre for the support polygon, shifted to the right, and placed in front. The pressure centres of both limbs were misaligned. The centre of pressure of the left limb was placed in front of it, the right one retroposed. The point of maximum pressure positioned in the left forefoot showed an evident overload on the right, equal to $60 \%$ of the overall weight. The distribution of the load between the forefoot and the hindfoot was uneven, with an evident overload in the forefoot area. The surfaces of the two feet were different from each other, with greater support on the right of $123 \mathrm{~cm}^{2}$ and $63 \mathrm{~cm}^{2}$ on the left. He had a right knee valgus angle of $172^{\circ}$, to the left of $165^{\circ}$. The two rear feet both had an angle of $175^{\circ}$. The initial inclination of the pelvis was $2^{\circ}$.

T2 assessment

STATIC ANALYSIS

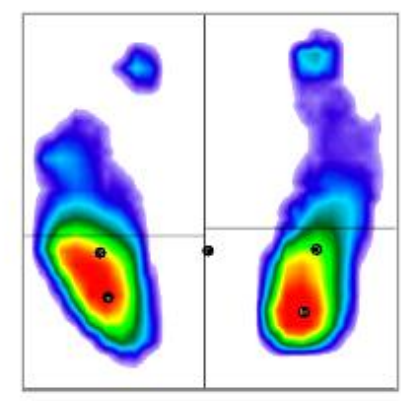

FRONT VIEW

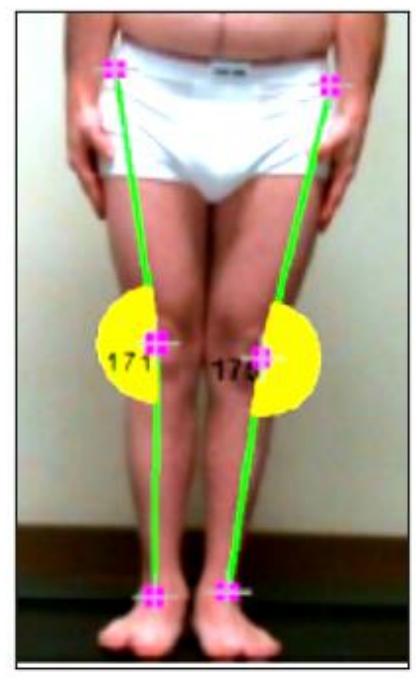

DYNAMIC ANALYSIS

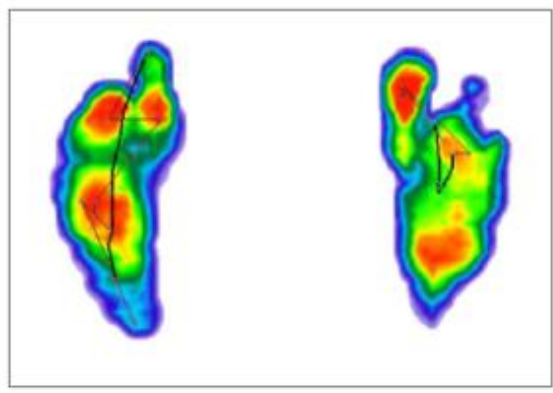

REAR VIEW

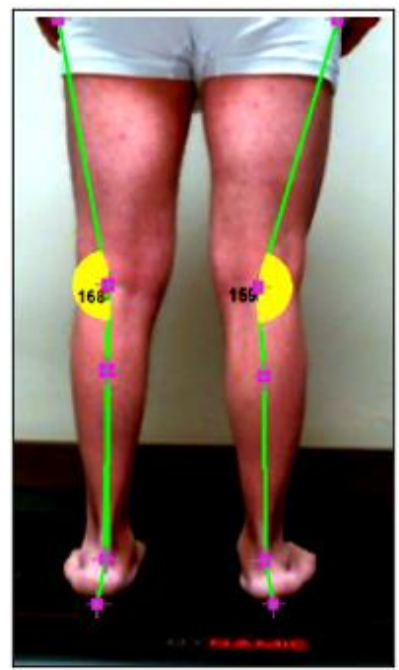

Figure 2. First Clinical Case T2.

At T2, the static examination carried out, presents the alignment of the pressure centres of the individual limbs, in line with the body's centre of gravity, while the centre of pressures is retroposed concerning the centre of the support polygon. The point of maximum pressure is positioned in the right retro-podalic area. The load distribution between the left and right limbs appears equally distributed, with a load distribution equal to $50 \%$ in both feet. The distribution of the load between the forefoot and rearfoot, both on the left and the right, indicates evident overloads in the retro-podalic part. The support surfaces of the two feet are quite 
similar to each other, with $94 \mathrm{~cm}^{2}$ on the left, and $102 \mathrm{~cm}^{2}$ on the right. Between the two fore-foot, however, a difference in the surface is detectable, greater on the right; while between the two rear feet, this difference is greater on the right, but not significant. In front view the valgus angle described by the knees is $171^{\circ}$ to the right and $175^{\circ}$ to the left. Both the rear feet are inclined $175^{\circ}$.

\section{Second Clinical Case}

\section{TO Evaluation}

From the static baropodometric evaluation, the pressure centre was placed in front of the centre of the support polygon and the pressure centres of the single limbs were misaligned; the left before it, while the right after it. The point of maximum pressure was positioned in the right retro-podalic part. The distribution of body weight on the two limbs indicated a good load distribution (50\% of the weight on the left, $50 \%$ on the right). The distribution of the load between the forefoot and the hindfoot, both on the left and the right, indicated evident overloads in the forefoot. The support surfaces of the two feet were quite similar to each other $\left(119 \mathrm{~cm}^{2}\right.$ on the left, $108 \mathrm{~cm}^{2}$ on the right). The knee had a width of $167^{\circ}$ to the right and $172^{\circ}$ to the left, with an overall inclination of the lower limbs equal to $266^{\circ}$. The valgus angle of the knee was $177^{\circ}$ to the right and $164^{\circ}$ to the left posteriorly, while the hindfoot angle of $167^{\circ}$ to the right and $179^{\circ}$ to the left, and pelvis inclination of $3^{\circ}$.

STATIC ANALYSIS

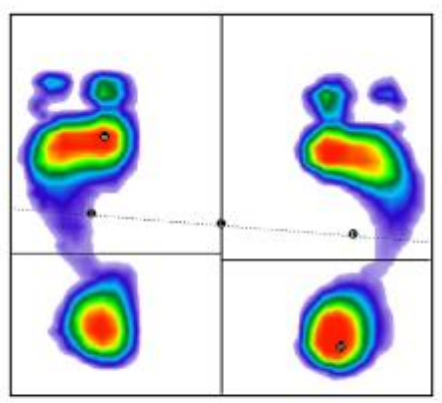

FRONT VIEW

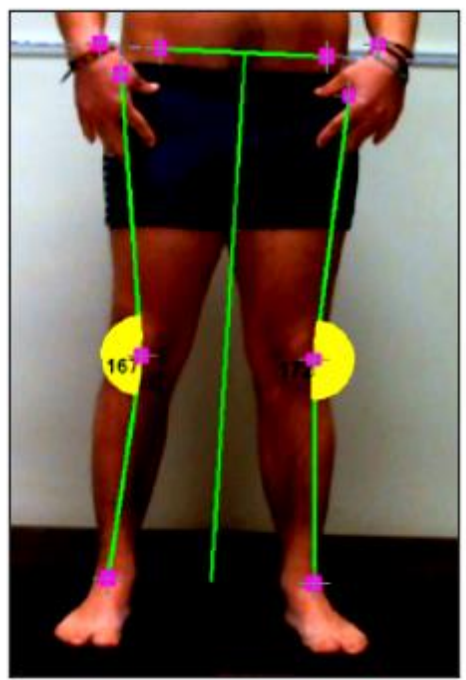

DYNAMIC ANALYSIS

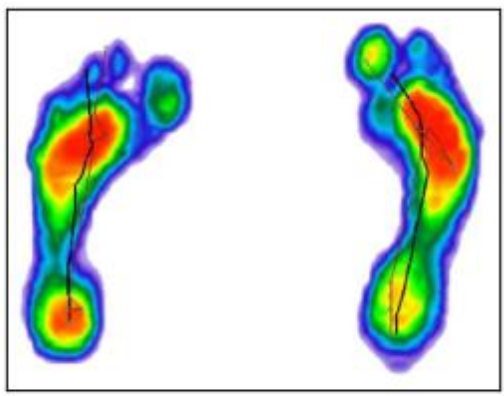

REAR VIEW

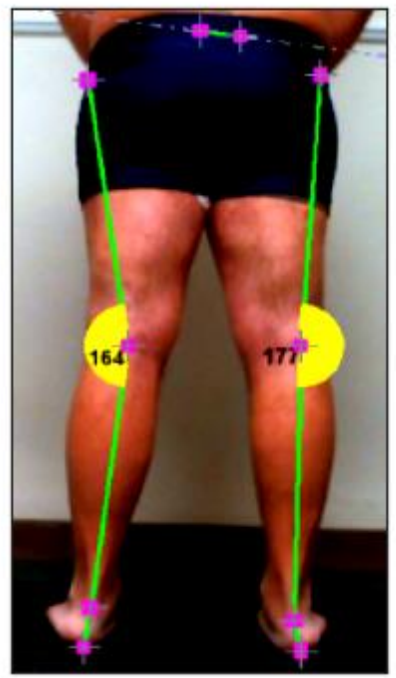

Figure 3. Second Clinical Case T0. 


\section{T2 assessment}

The body centre of gravity is cantered but preceded and the pressure centres of the left and right limbs are, according to the norm, aligned with each other. The point of greatest load is located in the right forefoot to indicate an excessive load concentration. The load distribution between the left and right limbs is normal and is equal to $48 \%$ of the weight on the left, and $52 \%$ on the right. The distribution of the load between the forefoot and the hindfoot, both on the left and the right, indicates evident overloads in the forefoot. The support surfaces of the two feet are quite similar to each other, with an area of $134 \mathrm{~cm}^{2}$ on the left, and $126 \mathrm{~cm}^{2}$ on the right. Between the two fore-foot and hindfoot, a moderate difference in the surface is detectable. In front view the angle of the right knee has a width of $167^{\circ}$ and $166^{\circ}$ to the left, with an overall inclination of the lower limbs of $268^{\circ}$. Posteriorly, the angle of the right knee is $171^{\circ}$ and $157^{\circ}$ to the left; while the right rear foot inclines $161^{\circ}$ and the left of $149^{\circ}$.

STATIC ANALYSIS

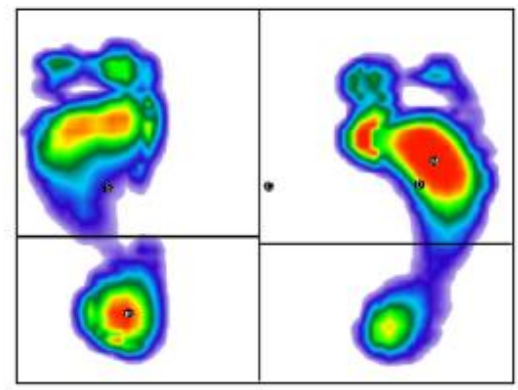

FRONT VIEW

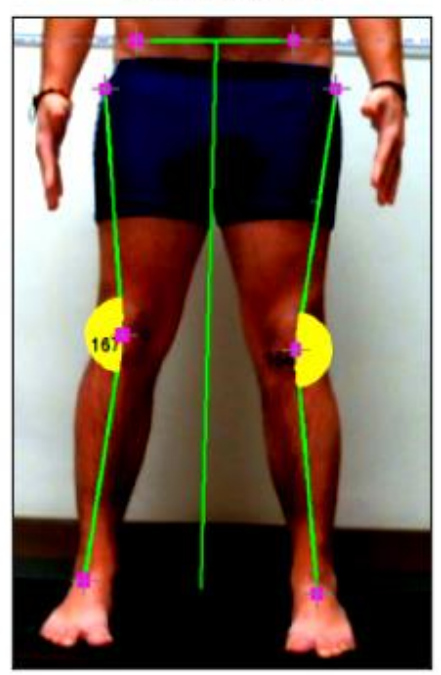

DYNAMIC ANALYSIS

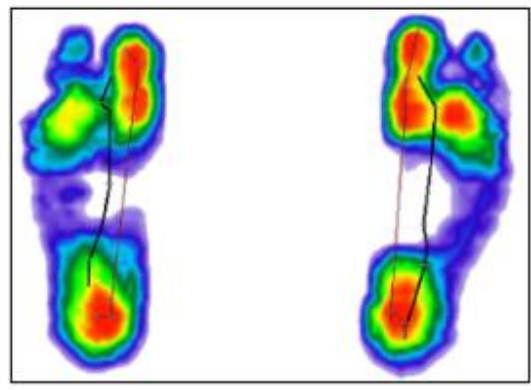

REAR VIEW

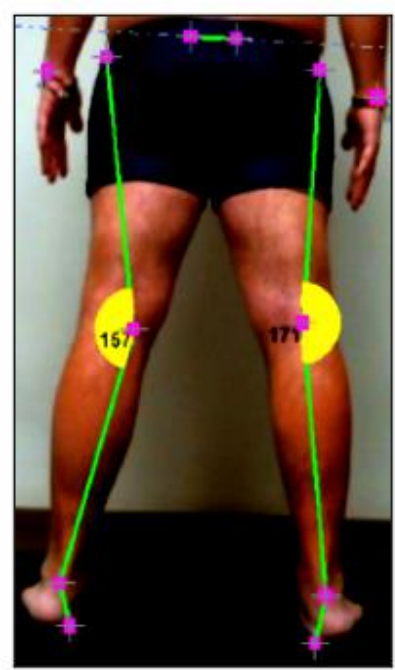

Figure 4. Second Clinical Case T2.

\section{Third Clinical Case}

\section{TO Evaluation}

The body centre of gravity was off-centre, concerning the overall support polygon, shifted to the left, and rearplaced. The pressure centres of both limbs were aligned with each other, but the distribution of body weight on the two limbs revealed overload on the left, equal to $54 \%$ of the overall weight. The distribution of the load between the forefoot and the hindfoot, both on the left and the right, indicated evident overloads in the retro- 
podalic part. An excessive difference in surface area was detected between the two fore-foot, greater on the right; while between the two rear feet, there was no appreciable difference in surface. The pelvis had an anterior inclination of $4^{\circ}$, with a valgus angle of $166^{\circ}$ in the right knee and $170^{\circ}$ in the left knee, for an overall inclination of the lower limbs equal to $269^{\circ}$. At the rear, the angle of the right knee was $171^{\circ}$ and $170^{\circ}$ to the left, while the right rear foot circumscribed an angle of $177^{\circ}$ and to the left of $170^{\circ}$.

STATIC ANALYSIS

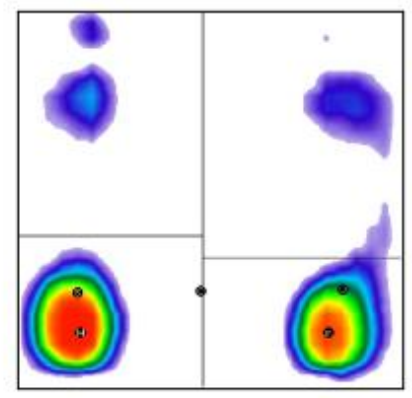

FRONT VIEW

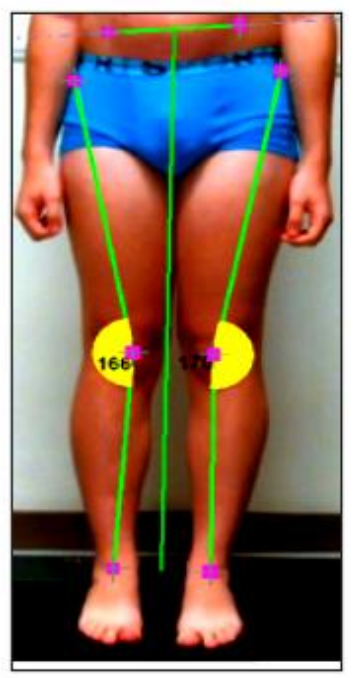

DYNAMIC ANALYSIS

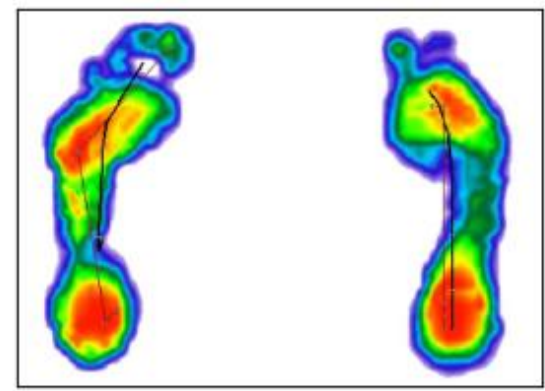

REAR VIEW

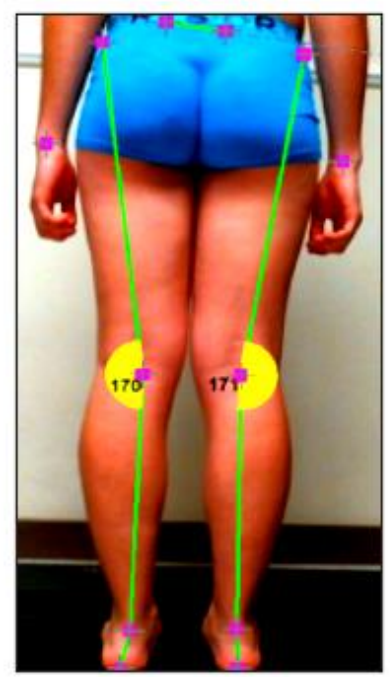

Figure 5. Third Clinical Case T0.

\section{T2 assessment}

The body centre of gravity, in the support polygon, is shifted to the left and rear-placed. The pressure centres of the individual limbs are misaligned and concerning the body centre of gravity, the left one is retroposed, the right one is in front. The point of maximum pressure is positioned, according to the standard, in the left retro-podalic part. The distribution of body weight on the two limbs indicates a good load distribution ( $50 \%$ of the weight on the left, $50 \%$ on the right). The distribution of the load between the forefoot and rearfoot, both on the left and the right, indicates evident overloads in the retro-podalic part. The surfaces of the two feet are different from each other with greater support on the right, where it occupies an area of $84 \mathrm{~cm}^{2}$ and $65 \mathrm{~cm}^{2}$ on the left. An excessive difference in surface area can be detected between the two fore-foot, greater on the right; between the two rear feet, a moderate difference in the surface is detectable, greater to the right. The basin is symmetrical, with zero inclination. The right knee has an angle of $168^{\circ}$ and to the left of $169^{\circ}$, with an overall inclination of the lower limbs equal to $269^{\circ}$. On the back, however, there is an inclination of 
$174^{\circ}$ in the right knee and $173^{\circ}$ in the left. The rear foot is instead inclined $174^{\circ}$ to the right and $180^{\circ}$ to the left.

STATIC ANALYSIS

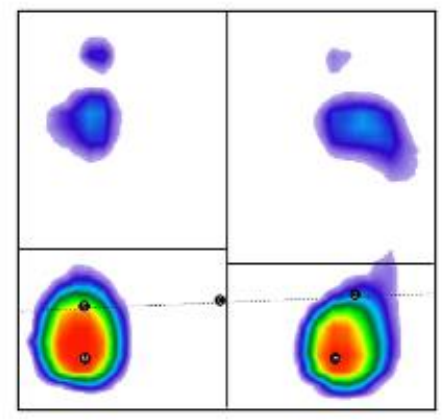

FRONT VIEW

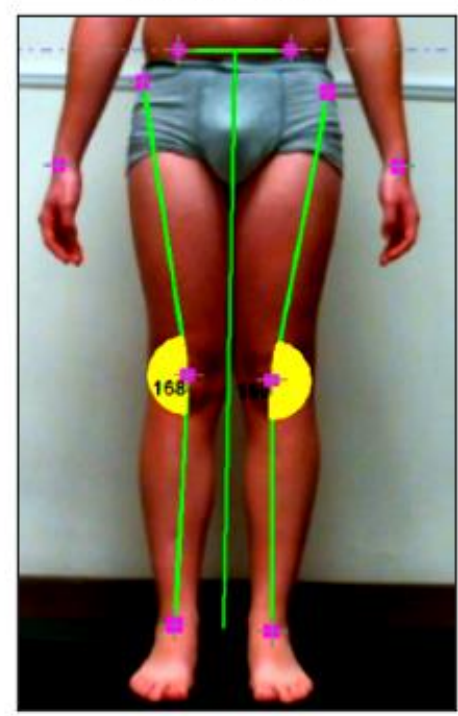

DYNAMIC ANALYSIS

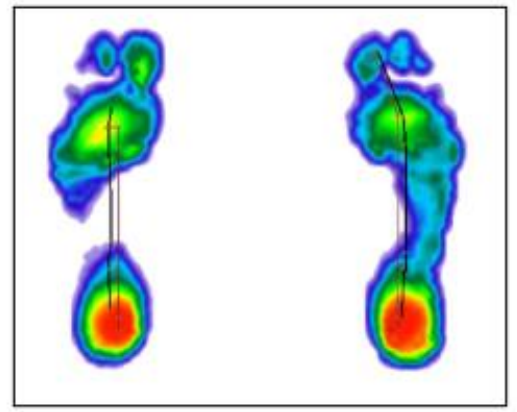

REAR VIEW

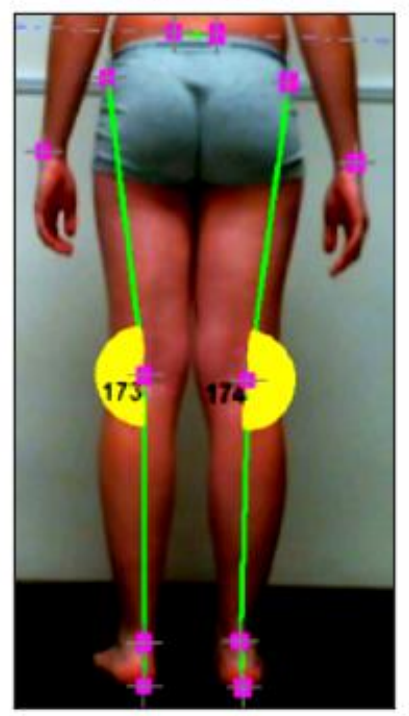

Figure 6. Third Clinical Case T2.

\section{Fourth Clinical Case}

\section{Evaluation TO}

The body centre of gravity was, in the support polygon, off-centre, shifted to the left and rear-placed; the pressure centres of the individual limbs, however, are misaligned. For the body's centre of gravity, the left one was rear-placed, the right one preceded. The point of maximum pressure was positioned in the left retropodalic part. The distribution of body weight on the two limbs revealed an evident overload on the right, equal to $56 \%$ of the overall weight. The distribution of body weight on the two limbs indicated a good load distribution ( $50 \%$ of the weight on the left, $50 \%$ on the right). The value of the load between the forefoot and the hindfoot on the left indicated an evident retro-podalic overload with $27 \%$ in the forefoot and $73 \%$ in the hindfoot, while on the right, it indicated a slight retro-podalic overload, equal to $41 \%$, in the forefoot and $59 \%$ in the rearfoot. An excessive difference in surface area was detected between the two fore-foot, greater on the right; between the two rear feet excessive difference in surface to the left. The valgus angle of the left knee was $166^{\circ}$ and $164^{\circ}$ to the right, with an inclination of the pelvis of $6^{\circ}$. At the rear, the angle of the right knee was $167^{\circ}$ and $161^{\circ}$ of the left. The right rear foot was tilted by $173^{\circ}$, the left by $168^{\circ}$. 
STATIC ANALYSIS

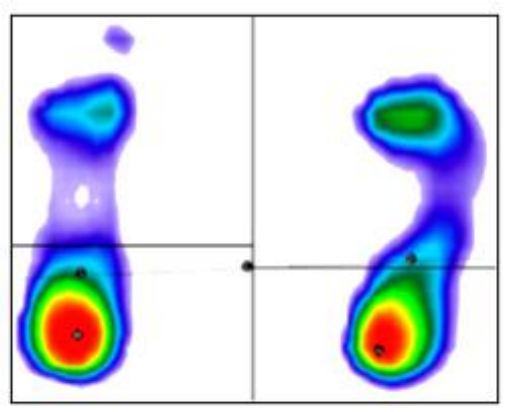

FRONT VIEW

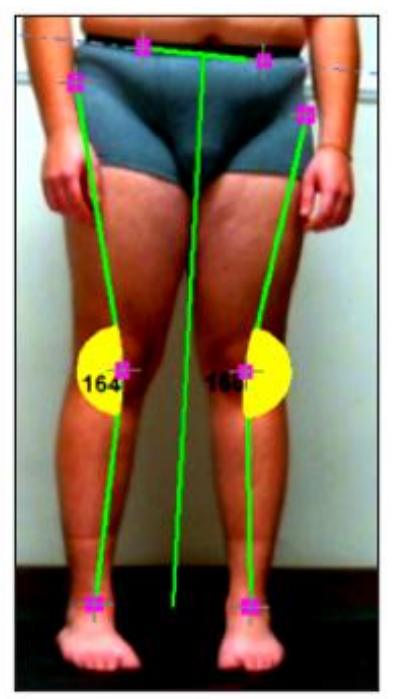

DYNAMIC ANALYSIS

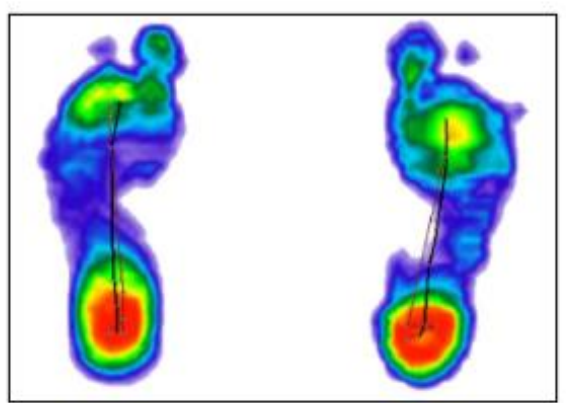

REAR VIEW

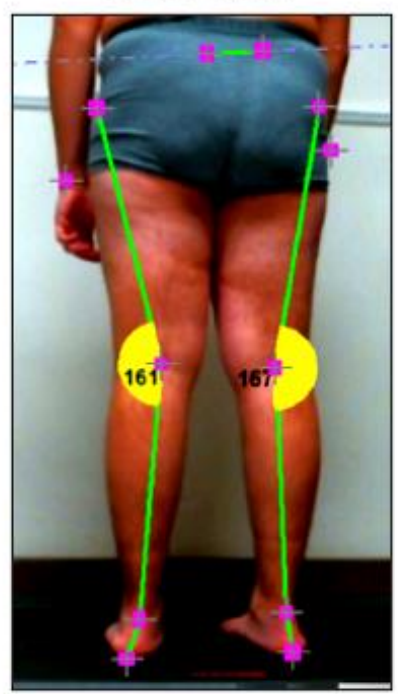

Figure 7. Fourth Clinical Case T0.

\section{T2 assessment}

The body's centre of gravity is aligned, as are the pressure centres. The point of greatest load is, as in the norm, positioned in the left retro-podalic area. The distribution of body weight on the two limbs is equal in both limbs. The surfaces of the two feet are slightly different from each other with greater support on the right, equal to $112 \mathrm{~cm}^{2}$ and $98 \mathrm{~cm}^{2}$ on the left. The angle of the left knee is $173^{\circ}$ and $169^{\circ}$ to the right, with an inclination of the lower limbs equal to $268^{\circ}$ and the pelvis of $3^{\circ}$. Posteriorly, the right knee presents an angle of $171^{\circ}$ and $172^{\circ}$ to the left. The hindfoot, on the right, is inclined in valgus by $171^{\circ}$, to the left by $176^{\circ}$. 
STATIC ANALYSIS

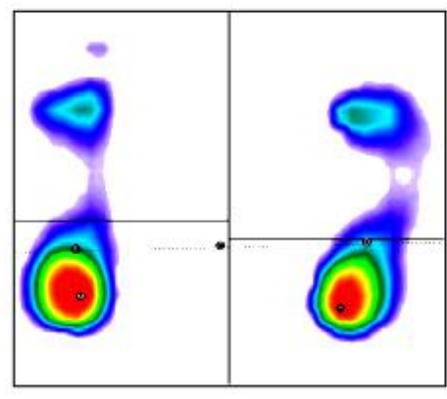

FRONT VIEW

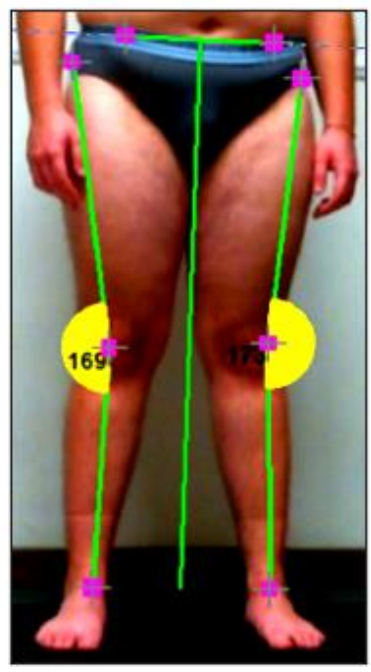

DYNAMIC ANALYSIS

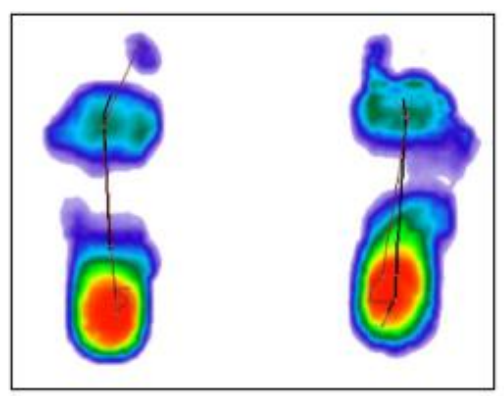

REAR VIEW

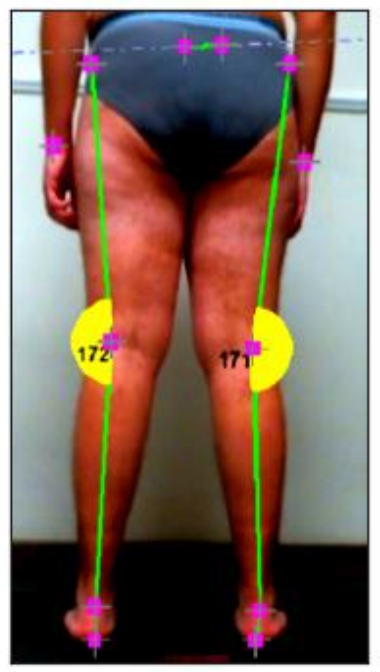

Figure 8. Fourth Clinical CaseT2.

\section{Fifth Clinical Case}

\section{TO Evaluation}

The body centre of gravity, in the support polygon, was slightly shifted to the left. The pressure centres of the individual limbs were misaligned. The centre of pressure of the right limb was placed in front of the left, retroposed. The point of maximum pressure was positioned, according to the norm, in the left retro-podalic part. The distribution of body weight on the two limbs revealed a moderate overload on the left (54\% of the overall weight). The value of the load between the forefoot and hindfoot on the left indicated an evident retropodalic overload (forefoot $31 \%$, hindfoot $69 \%$ ), while on the right an excessive forefoot overload (forefoot $55 \%$, hindfoot $45 \%$ ). The surfaces of the two feet were different from each other with greater support on the left (66 $\mathrm{cm}^{2}$ on the left, $58 \mathrm{~cm}^{2}$ on the right). A slight difference in surface area was detected between the two forefeet, greater on the left; between the two hind feet, there was an excessive difference in surface area, greater on the left. The pelvis was tilted by $5^{\circ}$, with similar angles to each other in the right knee of $174^{\circ}$ and the left of $175^{\circ}$. The overall inclination of the two limbs was $268^{\circ}$. On the back, the angle of the right knee was $174^{\circ}$ and $169^{\circ}$ on the left; while the rear foot is $176^{\circ}$ to the right and $177^{\circ}$. 
STATIC ANALYSIS

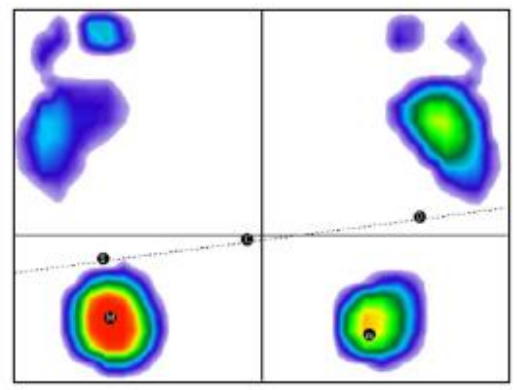

FRONT VIEW

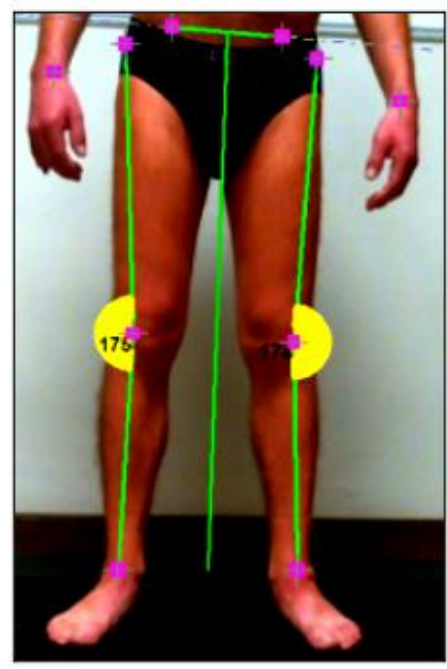

DYNAMIC ANALYSIS

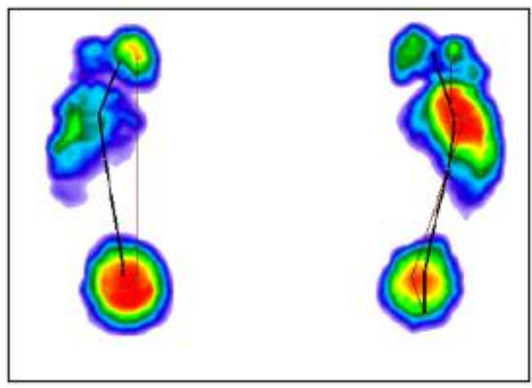

REAR VIEW

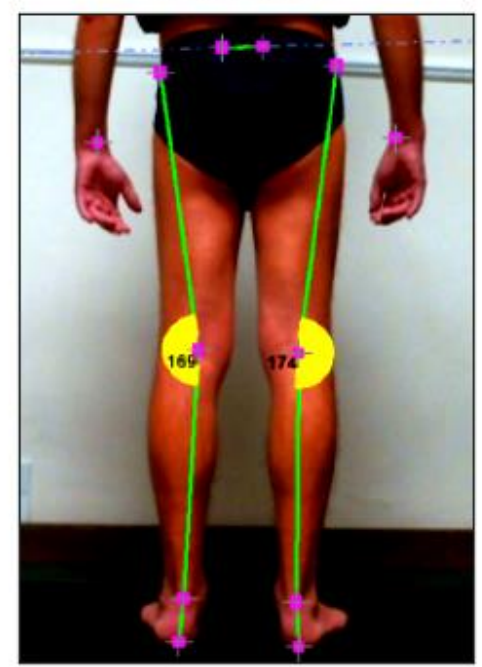

Figure 9. Fifth Clinical Case T0.

\section{T2 assessment}

The body centre of gravity $C$, in the support polygon, is displaced to the left and rear-placed. The pressure centres of the individual limbs are misaligned. The centre of pressure of the right limb is placed in front, the left one is retroposed. The point of maximum pressure is positioned, according to the standard, in the left retro-podalic part. The distribution of body weight on the two limbs reveals an evident overload on the left ( $56 \%$ of the overall weight). The distribution of the load between the forefoot and rearfoot, both on the left and the right, indicates evident overloads in the retro-podalic part. The support surfaces of the two feet are quite similar to each other $\left(58 \mathrm{~cm}^{2}\right.$ on the left, $53 \mathrm{~cm}^{2}$ on the right). There is a slight difference in the surface between the two forefeet, greater on the left; between the two rear feet, a moderate difference in the surface is detectable, greater on the left. The pelvis inclination is $4^{\circ}$, anteriorly the angle described by the right knee is $169^{\circ}$, while from the left it is $172^{\circ}$, with a global inclination of the lower limbs equal to $268^{\circ}$. On the back, on the other hand, there is an inclination of the sips equal to $7^{\circ}$, with an angle of the right knee of $173^{\circ}$ and $171^{\circ}$ in the left; in the right rear foot, on the other hand, there is an angle of $177^{\circ}$ and in the left one of $178^{\circ}$. 
STATIC ANALYSIS

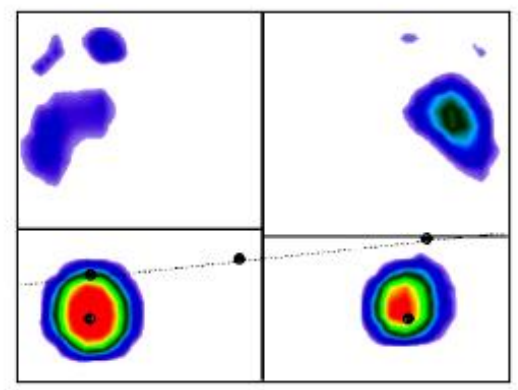

FRONT VIEW

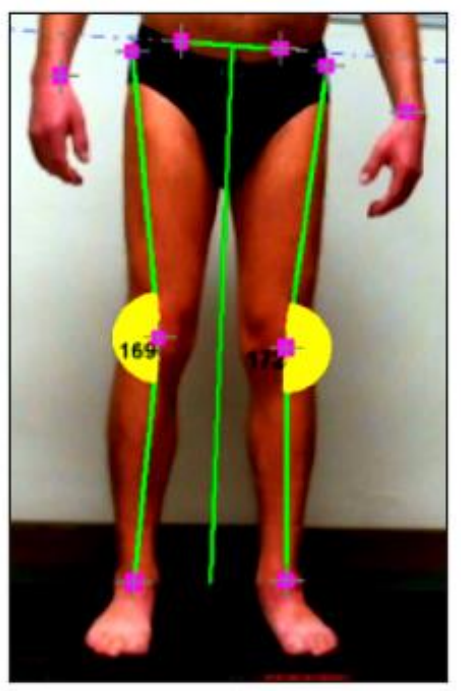

DYNAMIC ANALYSIS

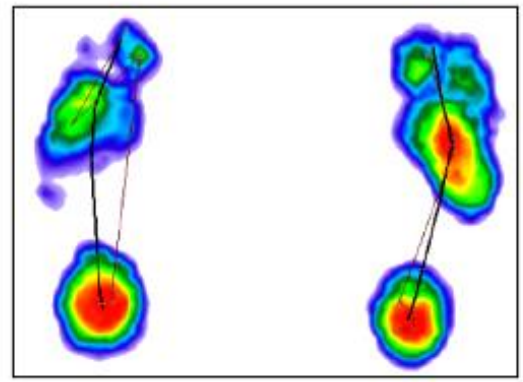

REAR VIEW

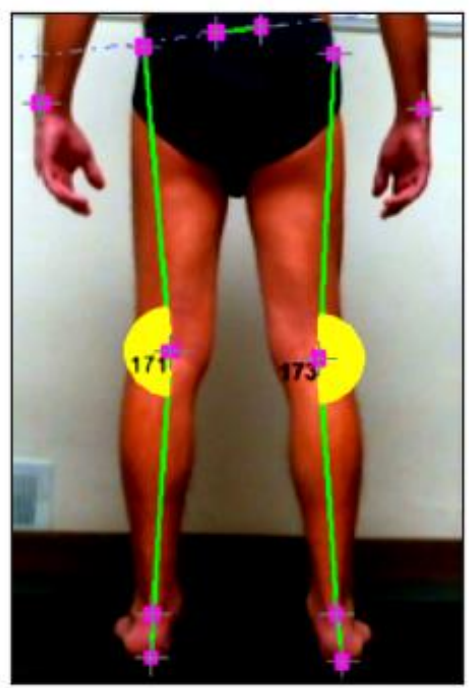

Figure 10. Fifth Clinical Case T2.

\section{Sixth Clinical Case}

\section{TO Evaluation}

From the static examination carried out on Sixth Case, the body centre of gravity was located in a decentralized position, concerning the overall support polygon and moved to the left and rear-placed. The pressure centres of the individual limbs were misaligned. Concerning the body's centre of gravity, the left one was rear-placed, the right one preceded. The load distribution between the left and right limbs showed an excessive overload on the left (57\% of the overall weight). The distribution of the load between the forefoot and the hindfoot, both on the left and the right, indicated evident overloads in the retro-podalic part. The surfaces of the two feet were different from each other, with greater support on the left $\left(74 \mathrm{~cm}^{2}\right.$ on the left, $66 \mathrm{~cm}^{2}$ on the right). An excessive difference in surface area was detected between the two rear feet, greater on the left. The pelvis was tilted of $3^{\circ}$, the right knee made an angle of $170^{\circ}$, while the left one of $169^{\circ}$; posteriorly, the angle formed by the right knee was $172^{\circ}$, the left $169^{\circ}$. The rear foot instead formed an angle of $170^{\circ}$ to the right, and of $168^{\circ}$ to the left. 
STATIC ANALYSIS

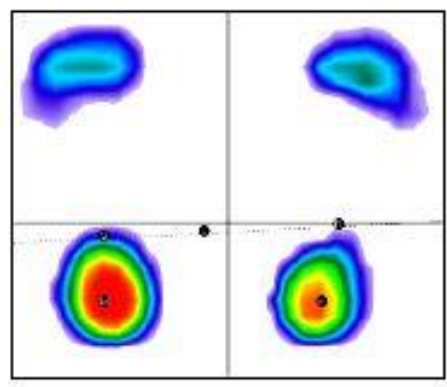

FRONT VIEW

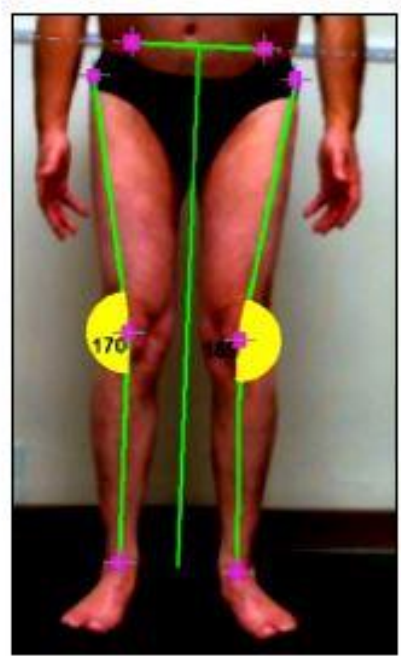

DYNAMIC ANALYSIS

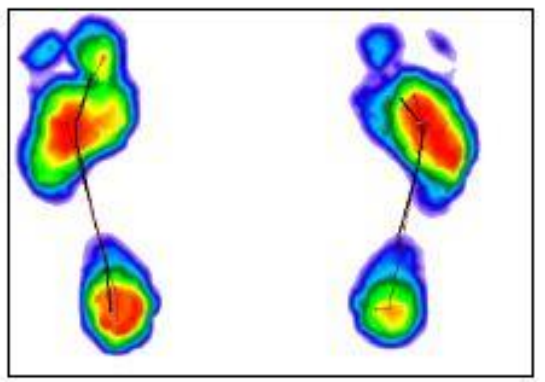

REAR VIEW

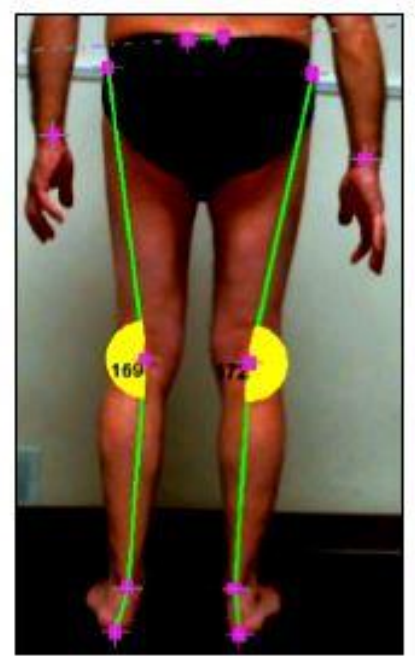

Figure 11. Sixth Clinical Case T0.

\section{T2 assessment}

From the static examination carried out on Sixth Case, it appears that the pressure centres of the individual limbs are misaligned. Concerning the body's centre of gravity, the left one is in front of it, the right one is backward. The point of maximum pressure is positioned, according to the standard, in the right retro-podalic part. The distribution of body weight on the two limbs shows a moderate overload on the right equal to $54 \%$ of the overall weight. The distribution of the load between the forefoot and rearfoot, both on the left and the right, indicates evident overloads in the retro-podalic part. The surfaces of the two feet are equal to each other, that is $54 \mathrm{~cm}^{2}$ of support for each foot. A moderate surface difference is detectable between the two hind feet, greater on the left, while a moderate surface difference is detectable between the two rear feet, greater on the right. The pelvis is tilted $2^{\circ}$, the right knee forms an angle of $169^{\circ}$, while the left one $170^{\circ}$. At the rear, the angle formed by the right knee is $170^{\circ}$, the left one is $168^{\circ}$. The rear foot forms an angle $169^{\circ}$ to the right, and $172^{\circ}$ to the left. 
STATIC ANALYSIS

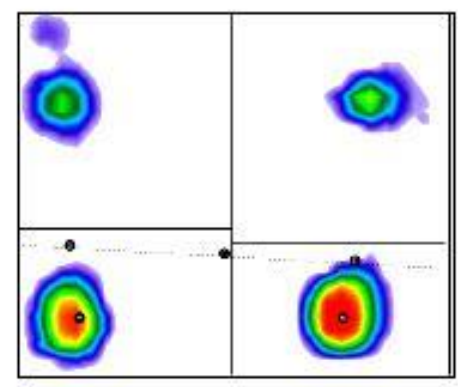

FRONT VIEW

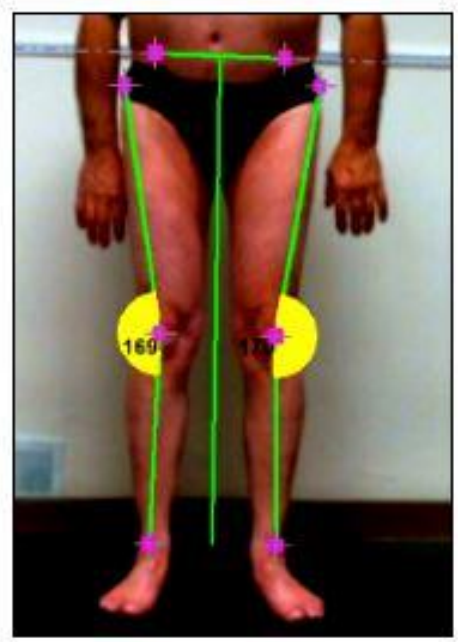

DYNAMIC ANALYSIS

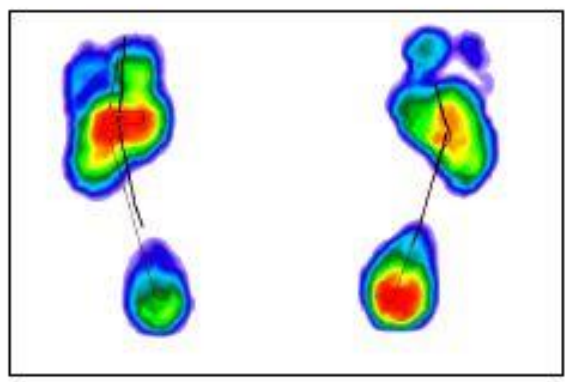

REAR VIEW

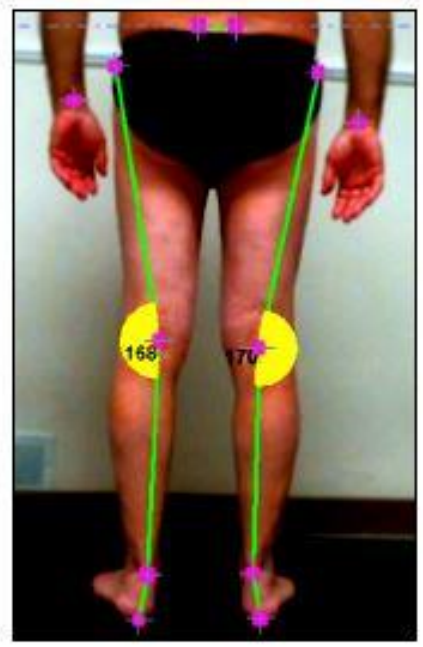

Figure 12. Sixth Clinical Case T2.

\section{Seventh Clinical Case}

\section{TO Evaluation}

The body centre of gravity was in a central position for the overall support polygon, with the pressure centres of the individual limbs misaligned. The centre of pressure of the right limb was placed in front of it, the left one was retroposed. The load distribution between the left and right limbs showed an excessive overload on the left (58\% of the overall weight). The left forefoot to hindfoot load value indicated obvious retro-podalic overload (forefoot $17 \%$, hindfoot $83 \%$ ), while on the right it indicated excessive forefoot overload (forefoot $62 \%$, hindfoot $38 \%$ ). The surfaces of the two feet were different from each other, with greater support on the right, equal to $98 \mathrm{~cm}^{2}$. The inclination of the pelvis was $4^{\circ}$ and the varus angle of the right knee was $162^{\circ}$, while the left one was $170^{\circ}$; overall the inclination of the lower limbs was $269^{\circ}$. At the rear, the inclination of the sips was $20^{\circ}$, with the valgus angle to the right of the knee equal to $169^{\circ}$ and $170^{\circ}$ to the left. The rear foot was inclined $171^{\circ}$ to the right and $175^{\circ}$ to the left. 
STATIC ANALYSIS

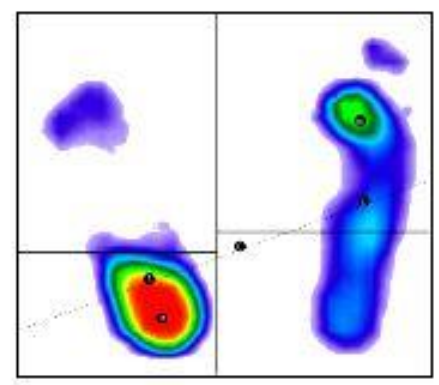

FRONT VIEW

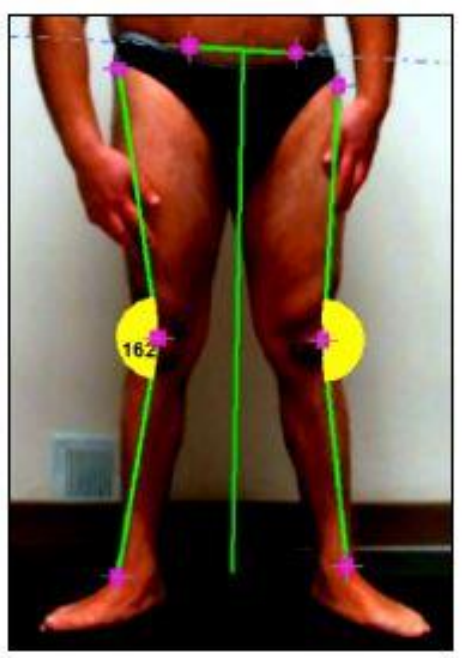

DYNAMIC ANALYSIS

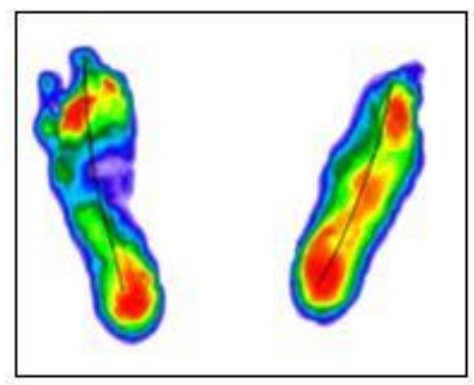

REAR VIEW

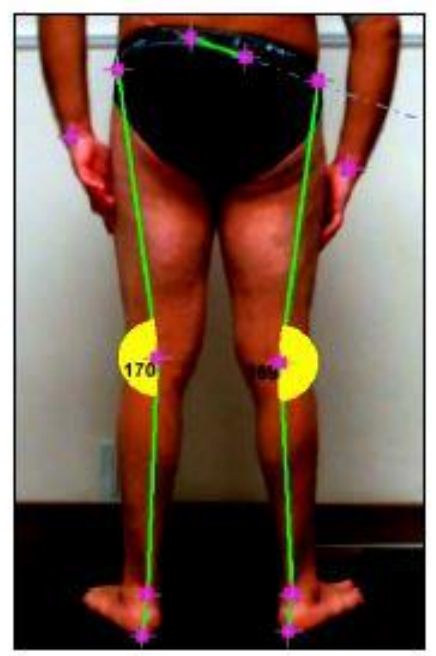

Figure 13. Seventh Clinical Case T0.

\section{T2 assessment}

The body centre of gravity is central to the overall support polygon, but the pressure centres of the individual limbs are misaligned. The centre of pressure of the right limb is placed in front, the left one is retroposed. The point of maximum pressure is positioned, according to the standard, in the left retro-podalic part. The distribution of body weight on the two limbs shows a moderate overload on the left, equal to $55 \%$ of the overall weight. The value of the load between the forefoot and hindfoot, on the left, indicates an evident retropodalic overload (forefoot $22 \%$, hindfoot $78 \%$ ), while on the right it indicates an excessive forefoot overload (forefoot $57 \%$, hindfoot $43 \%$ ). The support surfaces of the two feet are quite similar to each other $\left(93 \mathrm{~cm}^{2}\right.$ on the left, $102 \mathrm{~cm}^{2}$ on the right). An excessive difference in surface area is detectable between the two forefeet, greater on the right, while between the two rear feet, an excessive difference in the surface is detectable, greater on the left. The inclination of the pelvis is $12^{\circ}$; on the front, the valgus angle of the right knee is equal to $168^{\circ}$ and $169^{\circ}$ to the left, as well as the inclination of the lower limbs equal to $268^{\circ}$. 
STATIC ANALYSIS

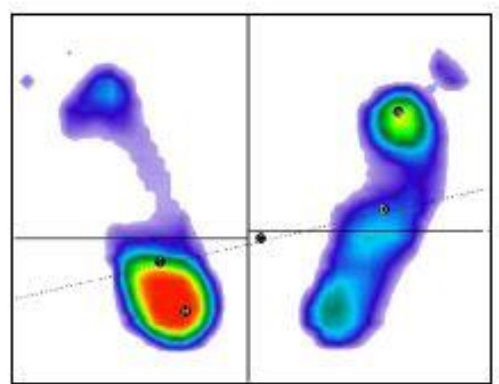

FRONT VIEW

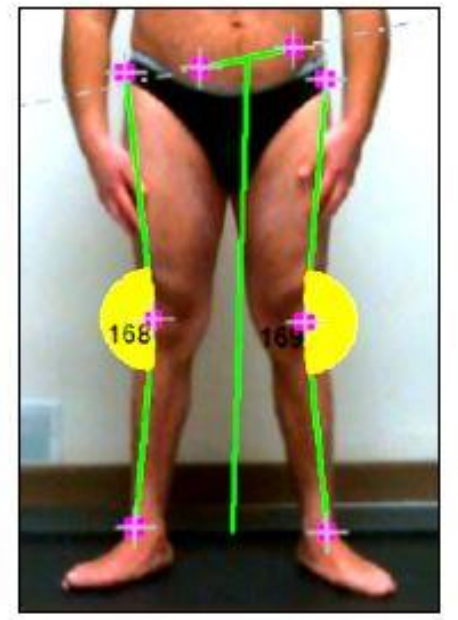

DYNAMIC ANALYSIS

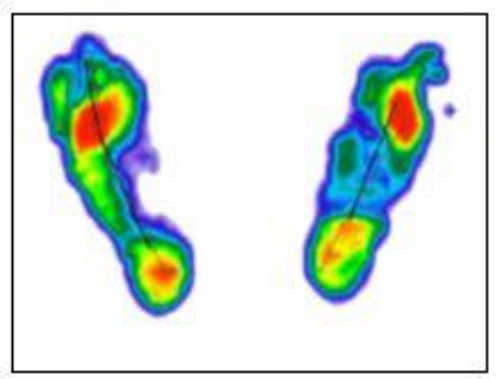

REAR VIEW

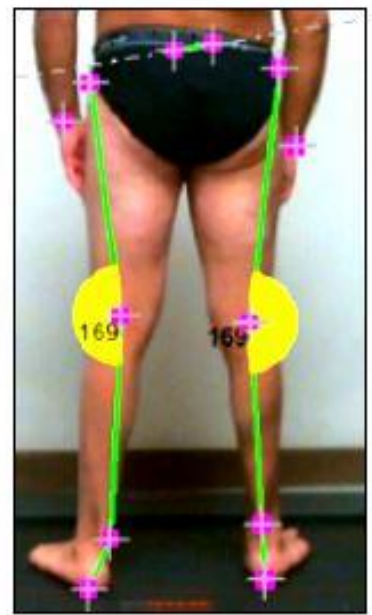

Figure 14. Seventh Clinical Case T2.

\section{Eighth Clinical Case}

\section{TO Evaluation}

The centre of the pressures was placed in front of the centre of the support polygon and the pressure centres of the individual limbs are aligned with each other. The load distribution between the left and right limbs showed a slight overload on the right, equal to $54 \%$ of the overall weight. The value of the load between the forefoot and hindfoot on the left indicated a modest retro-podalic overload (forefoot $48 \%$, hindfoot $52 \%$ ), as well as on the right (forefoot $47 \%$, hindfoot $53 \%$ ). The support surfaces of the two feet were quite similar to each other, with an area of $120 \mathrm{~cm}^{2}$ on the left and $110 \mathrm{~cm}^{2}$ on the right. The right knee had a valgus angle of $164^{\circ}$ to the right and $166^{\circ}$ to the left and a pelvic tilt of $4^{\circ}$. At the rear, the angle of both knees was $165^{\circ}$, while the angle of the right hind foot was $175^{\circ}$, to the left of $170^{\circ}$. 
STATIC ANALYSIS

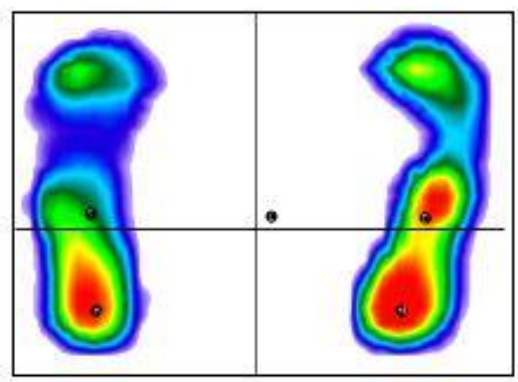

FRONT VIEW

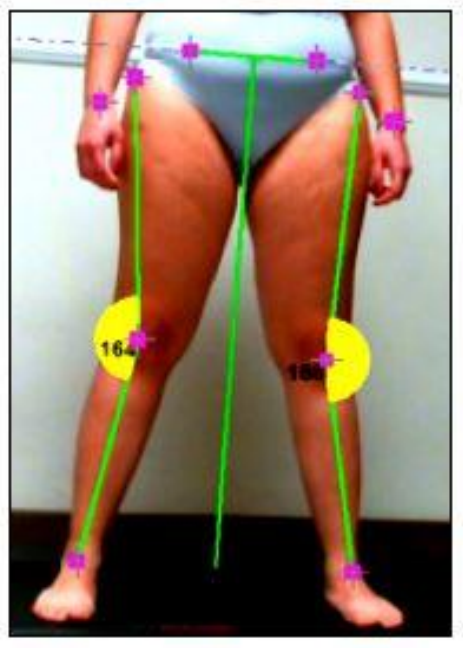

DYNAMIC ANALYSIS

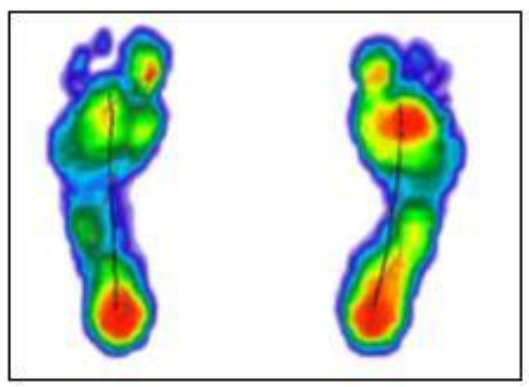

REAR VIEW

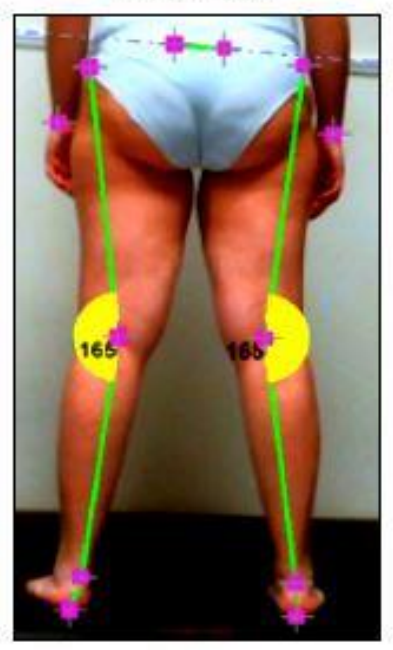

T2 assessment

Figure 15. Eighth Clinical Case T0.

The pressure centres of the individual limbs are well aligned with each other and in line with the body's centre of gravity. The point of maximum pressure is positioned in the right-rear part of the pod. The distribution of body weight on the two limbs indicates a good load distribution (48\% of the weight on the left, $52 \%$ on the right). The value of the forefoot to hindfoot load on the left indicates a slight forefoot overload (forefoot $48 \%$, hindfoot $52 \%$ ), while on the right it indicates excessive forefoot overload (forefoot $52 \%$, hindfoot $48 \%$ ). The support surfaces of the two feet are quite similar to each other $\left(128 \mathrm{~cm}^{2}\right.$ on the left, $121 \mathrm{~cm}^{2}$ on the right). Between the two forefeet, a moderate difference in the surface is detectable, greater on the left, as well as between the two rear feet. In front view the knees have an angle of $164^{\circ}$ to the right and $166^{\circ}$ to the left. The pelvis is inclined by $1^{\circ}$. The right rear foot is instead inclined by $177^{\circ}$, to the left instead of $166^{\circ}$; while the knees present an angle of $164^{\circ}$ to the right and $162^{\circ}$ to the left on the back. 
STATIC ANALYSIS

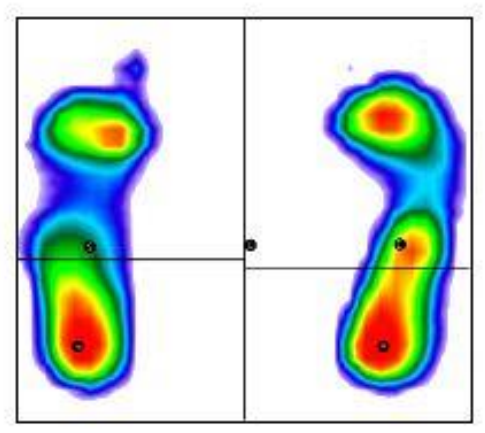

FRONT VIEW

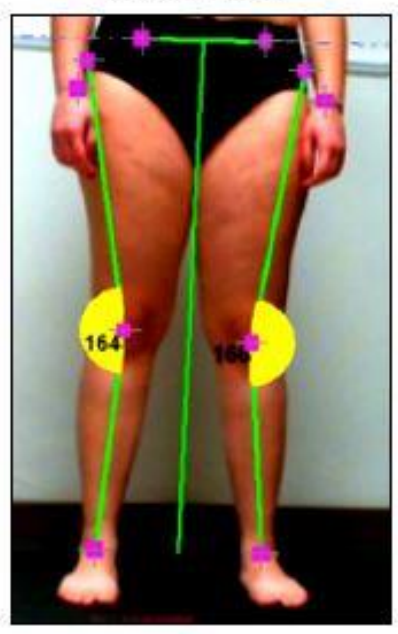

DYNAMIC ANALYSIS

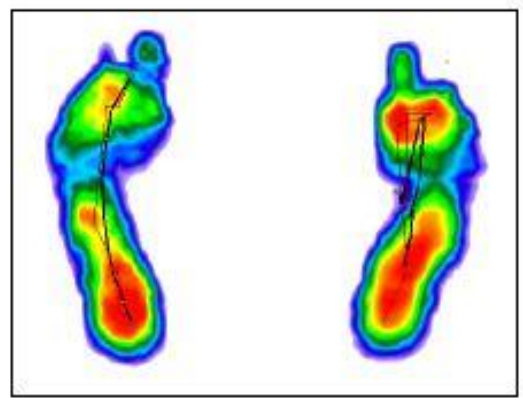

REAR VIEW

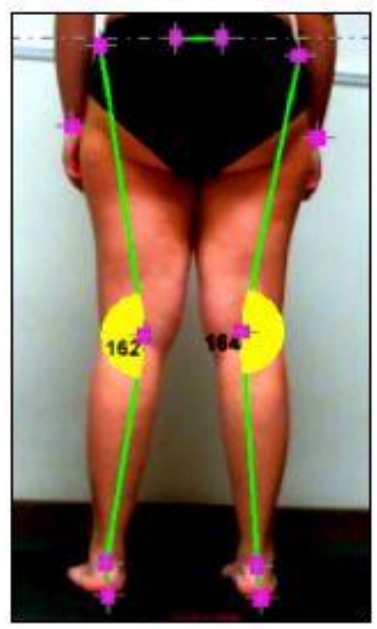

Figure 16. Eighth Clinical Case T2.

\section{Ninth Clinical Case}

\section{TO Evaluation}

The body centre of gravity in the support polygon was off-centre, shifted to the left, and rear-placed. The pressure centres of the left and right limbs were not in line with each other. The centre of pressure of the right limb was placed in front of it, the left one was retroposed. The point of maximum pressure was positioned in the left retro-podalic part. The value of the load between the forefoot and the hindfoot on the left indicated an evident retro-podalic overload (forefoot 38\%, hindfoot 62\%). The surfaces of the two feet were different from each other, with greater support on the right $\left(147 \mathrm{~cm}^{2}\right.$ on the left, $170 \mathrm{~cm}^{2}$ on the right). An excessive difference in surface area was detected between the two forefeet, greater on the right, while between the two rear feet it was moderate. Anteriorly, the pelvis was asymmetrical with an inclination of $6^{\circ}$, while the right knee circumscribed an angle of $168^{\circ}$, and to the left of $163^{\circ}$. On the back, on the other hand, the angle of the right knee was $161^{\circ}$ wide and the rear foot was inclined by $178^{\circ}$, while on the left the knee angle was $154^{\circ}$ and the rear foot was $174^{\circ}$. 
STATIC ANALYSIS

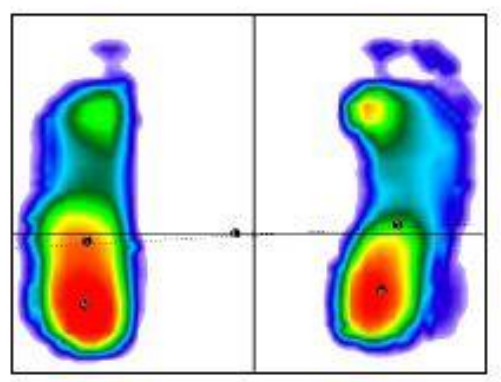

FRONT VIEW

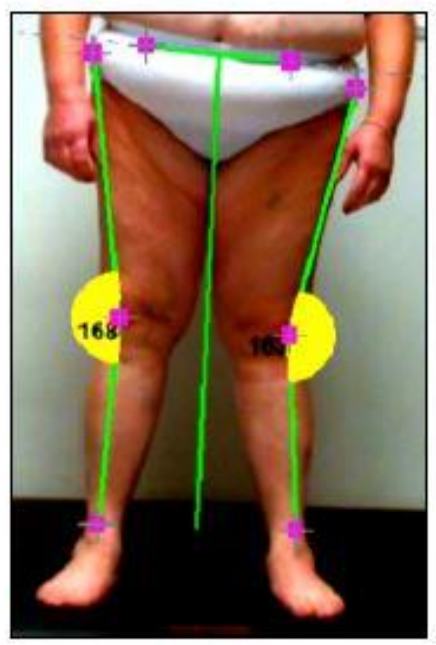

DYNAMIC ANALYSIS

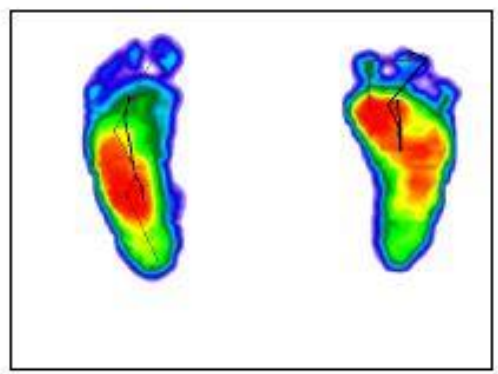

REAR VIEW

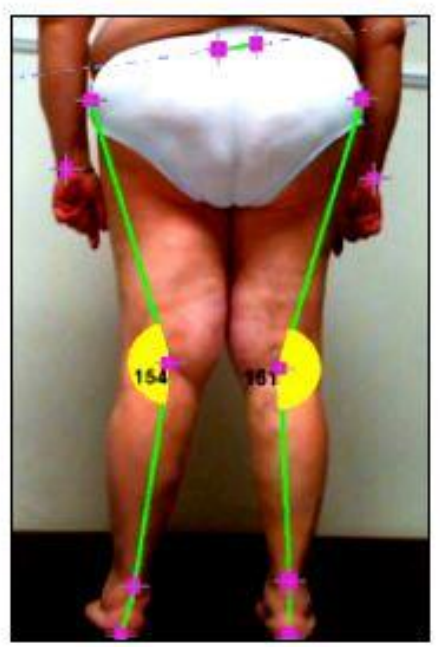

Figure 17. Ninth Clinical Case T0.

\section{T2 assessment}

The body centre of gravity is in a central position concerning the overall support polygon, but the pressure centres of the individual limbs are misaligned. The centre of pressure of the right limb is placed in front, the left one is retroposed. The point of maximum pressure is positioned in the right retro-podalic part. The distribution of body weight on the two limbs reveals a significant overload on the right $(53 \%$ of the overall weight). The value of the load between the forefoot and hindfoot on the left is within the physiological values, while on the right it indicates a slight forefoot overload (forefoot $48 \%$, hindfoot $52 \%$ ). The support surfaces of the two feet are quite similar to each other $\left(120 \mathrm{~cm}^{2}\right.$ on the left, $132 \mathrm{~cm}^{2}$ on the right). An excessive difference in surface area can be detected between the two forefeet, greater on the right; between the two rear feet, there is no appreciable difference in surface area. Front the pelvis is asymmetrical and inclines $10^{\circ}$, while the right knee circumscribes an angle of $170^{\circ}$, and to the left of $159^{\circ}$. On the back, on the other hand, the angle of the right knee has a width of $163^{\circ}$, and the rear foot is inclined by $177^{\circ}$, while on the left the angle of the knee is $156^{\circ}$ and of the rear foot of $179^{\circ}$. 
STATIC ANAL YSIS

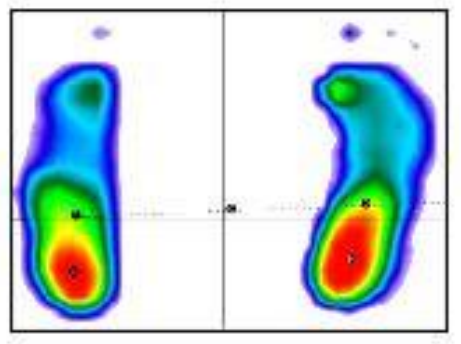

FRONT VIEW

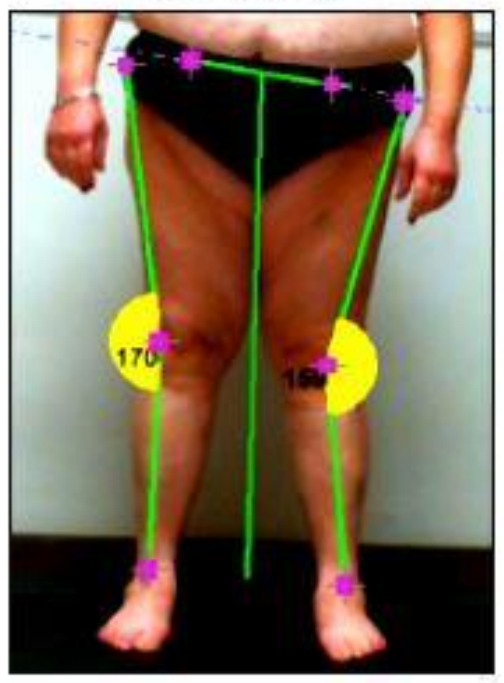

\section{DYNAMIC ANALYSIS}

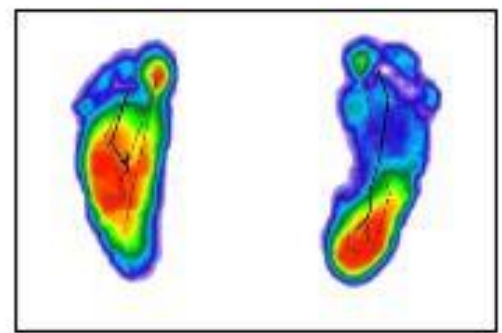

REAR VIEW

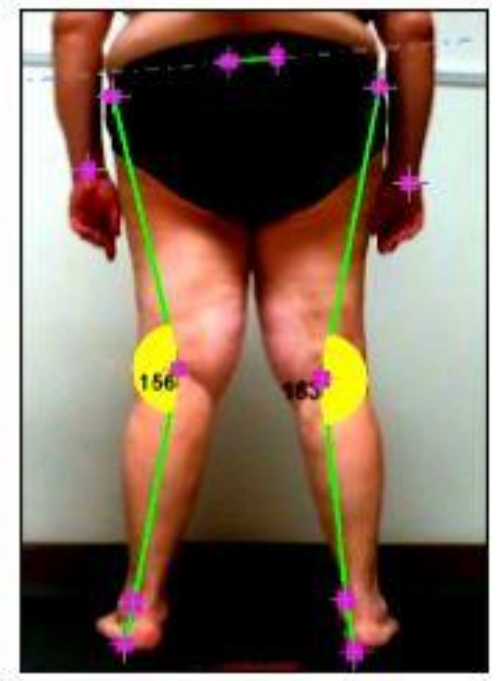

Figure 18. Ninth Clinical Case T2.

\section{Tenth Clinical Case}

\section{TO Evaluation}

The body centre of gravity, in the support polygon, was shifted to the left and rear-placed. The pressure centres of the individual limbs were well aligned with each other and in line with the body's centre of gravity. The point of maximum pressure was positioned, according to the norm, in the left retro-podalic part. The load distribution between the left and right limbs showed an excessive overload on the left (56\% of the overall weight). The distribution of the load between the forefoot and the hindfoot, both on the left and the right, indicated evident overloads in the retro-podalic part. The surfaces of the two feet were equal to each other, equal to $48 \mathrm{~cm}^{2}$ of support for each foot. A slight difference in surface area was detected between the two forefeet, greater on the right, while between the two rear feet, a slight difference in the surface was detected, greater on the left. In front view the pelvis was inclined by $2^{\circ}$, the left knee angle was $166^{\circ}$, while it was $171^{\circ}$ to the right. 
STATIC ANALYSIS

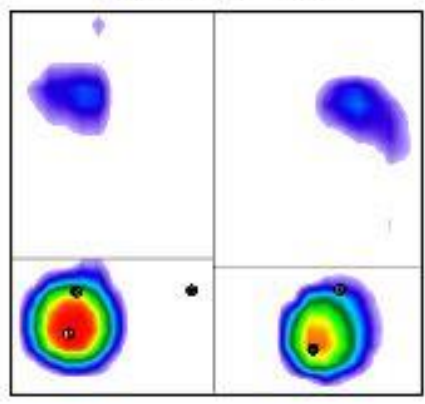

FRONT VIEW

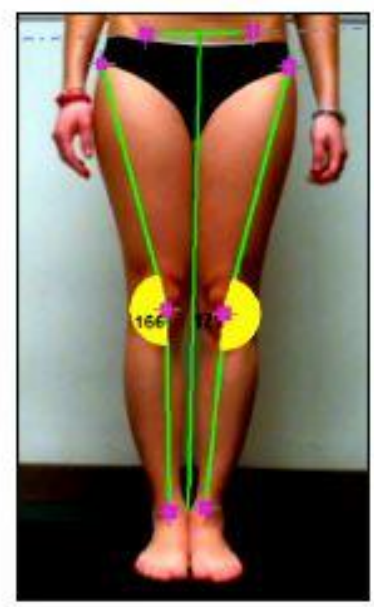

DYNAMIC ANALYSIS

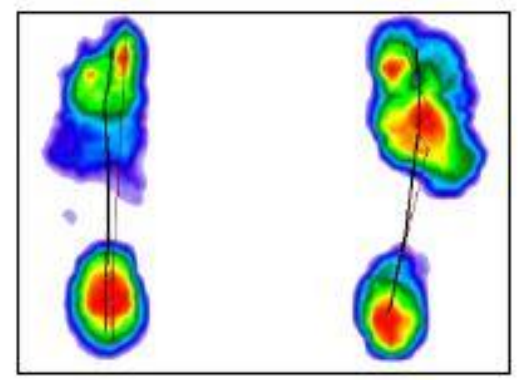

REAR VIEW

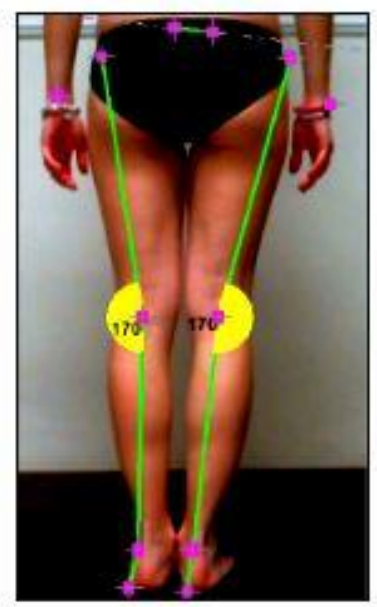

Figure 19. Tenth Clinical Case T0.

\section{T2 assessment}

The body centre of gravity, in the support polygon, is shifted to the left and rear-placed. The pressure centres of the individual limbs are misaligned. The centre of pressure of the right limb is placed in front, the left one is retroposed. The point of maximum pressure is positioned, according to the standard, in the left retro-podalic part. The distribution of body weight on the two limbs reveals a significant overload on the left equal to $53 \%$ of the overall weight. The distribution of the load between the forefoot and rearfoot, both on the left and the right, indicates evident overloads in the retro-podalic part. The surfaces of the two feet are different from each other with greater support on the right; the surface is $65 \mathrm{~cm}^{2}$ on the left, $74 \mathrm{~cm}^{2}$ on the right. In front view the pelvis is inclined of $4^{\circ}$; the left knee angle is $169^{\circ}$, as is the right one. On the back, however, the right angle of the knee is $173^{\circ}$, the left is $176^{\circ}$; the right rear foot forms an angle of $175^{\circ}$, while the left is $171^{\circ}$. 
STATIC ANALYSIS

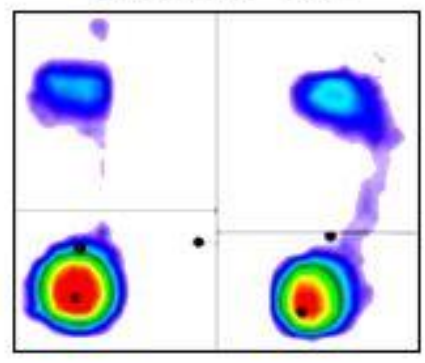

FRONT VIEW

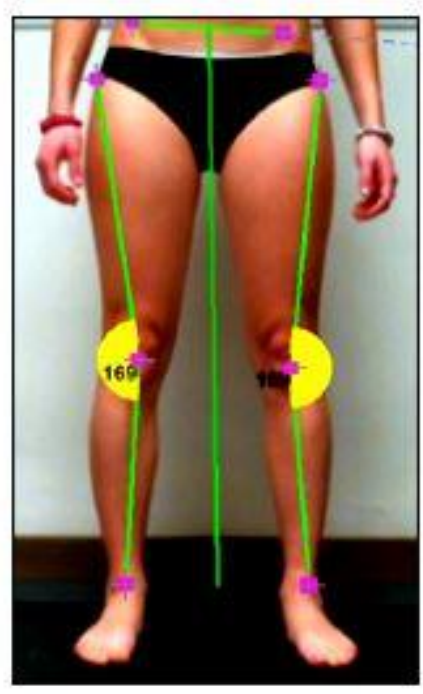

DYNAMIC ANALYSIS

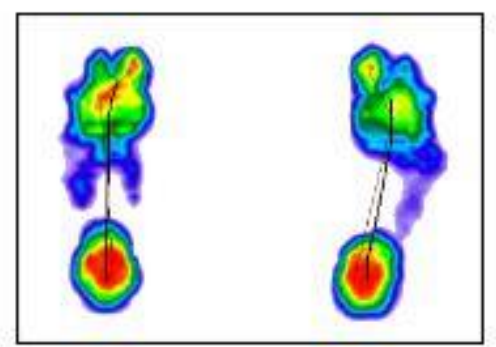

REAR VIEW

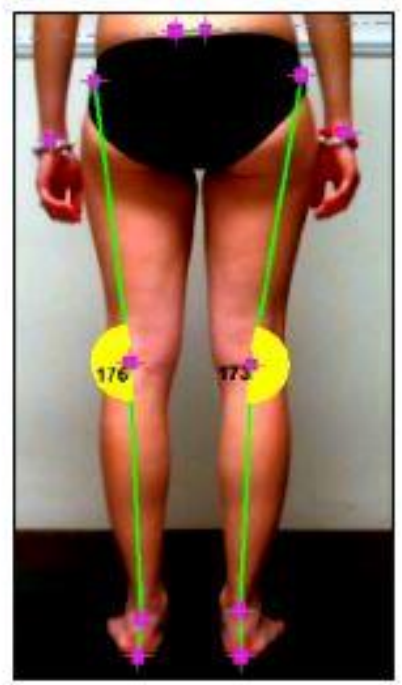

Figure 20. Tenth Clinical Case T2.

\section{CONCLUSION}

Starting from the consideration that subjects with DS presented in principle the same postural pattern and that this could be a source of predisposition for pathologies at the expense of the Musculoskeletal System we intervened with personalized physical exercise protocols to improve postural alterations. We evaluated them globally and treated them with the same exercises of proprioception and muscle strengthening with which we would treat subjects not affected by DS but presenting everything in the form of a game.

Through an initial evaluation (T0) and a final (T2), we took data on the variations that through the physical exercise we induced by interacting with the tonic-postural system. The evaluation of the data shows a better distribution of the podalic load on both feet both as regards the ratio of both feet and as regards the distribution between forefoot and rearfoot. Also, from baropodometry, it is possible to identify a reduction in podalic overload points. This is associated in 7 out of 10 cases with an improvement, in terms of joint degrees, in the position of the hip, knee, ankle, and foot joints. This is configured with a reduction of the anteversion of the pelvis, a reduction in the valgism of the knees, a reduction of the valgism of the rearfoot, and an elevation of the plantar vault. 
We can conclude by saying that motor treatment is an important method of treating paramorphisms of the lower limb even in the case of subjects with Down Syndrome that translates into prevention and mitigation of the pathologies from which they suffer, improving daily life, autonomy, and quality of life.

\section{REFERENCES}

Agiovlasitis S, McCubbin JA, Yun J, et al. . Economy and preferred speed of walking in adults with and without Down syndrome. Adapt Phys Activ Q 2009;26:118-30. https://doi.org/10.1123/apaq.26.2.118

Anwar AJ, Walker JD, Frier BM. Type 1 diabetes mellitus and Down's syndrome: prevalence, management and diabetic complications. Diabet Med. 1998;15(2):160-163. https://doi.org/10.1002/(SICI)1096-9136(199802)15:2<160::AID-DIA537>3.0.C0;2-J

Bennet GC, Rang M, Roye DP, Aprin H.Dislocation of the hip in trisomy 21.J Bone Joint Surg Br.1982;64:289-294. https://doi.org/10.1302/0301-620X.64B3.6212586

Bertapelli F, Pitetti K, Agiovlasitis S, Guerra-Junior G. Overweight and obesity in children and adolescents with Down syndrome-prevalence, determinants, consequences, and interventions: A literature review. Res Dev Disabil. 2016 Oct;57:181-92. https://doi.org/10.1016/j.ridd.2016.06.018

Caird MS, Wills BP, Dormans JP. Down syndrome in children: the role of the orthopaedic surgeon. J Am Acad Orthop Surg 2006;14:610-9. https://doi.org/10.5435/00124635-200610000-00003

Chang CL, Kubo M, Ulrich BD. Emergence of neuromuscular patterns during walking in toddlers with typical development and with Down syndrome. Hum Mov Sci 2009;28:283-96. https://doi.org/10.1016/j.humov.2008.12.002

Cimolin V, Galli M, Grugni G, Vismara L, Albertini G, Rigoldi C, Capodaglio P. Gait patterns in PraderWilli and Down syndrome patients. J Neuroeng Rehabil. 2010 Jun 21;7:28. https://doi.org/10.1186/1743-0003-7-28

Cristofalo MG, Parisi A, Francavilla V, Savojardo M, Galiano S, Pecorella G, Marchese L, Palmeri F, Lo Coco L, Francavilla G. Posture: art and science at the athletes' service. La postura: arte e scienza al servizio degli atleti. Med. Sport 1998;52:99-104.

Di Maio G, Monda V, Messina A, Polito R, Monda M, Tartaglia N, Ambrosio A, Pisanelli D, Asmundo A, Di Nunno N, Ametta A, Villano I, Francavilla VC. Physical activity and modification of lifestyle induce benefits on the health status. Acta Medica Mediterranea. 2020 Jen; 36(3):1913-1919.

Eid MA, Aly SM, Huneif MA, Ismail DK. Effect of isokinetic training on muscle strength and postural balance in children with Down's syndrome. Int J Rehabil Res. 2017 Jun;40(2):127-133. https://doi.org/10.1097/MRR.0000000000000218

Farquhar JW. Early-onset diabetes in the general and the Down's syndrome population. Lancet. 1969;2(7615):323-324. https://doi.org/10.1016/S0140-6736(69)90087-7

Fischetti F, Cataldi S, Bonavolontà V, Francavilla VC, Panessa P, Messina G. Hypertrophic adaptation of lower limb muscles in response to three different resistance training regimens. Acta Medica Mediterranea. 2020 Aug; 36: 3235.

Francavilla VC, Bongiovanni T, Todaro L, Genovesi F, Francavilla G. Risk factors, screening tests and prevention strategies of muscle injuries in élite soccer players: a critical review of the literature. Med Sport 2016;69:134-50.

Francavilla G, Francavilla VC. Physical exercise is terapy - L'attività motoria è terapia. Med. Sport 2013; Vol.66:625-8.

Francavilla VC, La Sala F, Palmieri F, Panicucci G, Parisi A, Francavilla G. The senso motor replanning in the recurrence prevention of sprained ankle : six months-evalutation in basket-ball players. La riprogrammazione senso-motoria nella prevenzione delle recidive di distorsione di caviglia: valutazione a 6 mesi in giocatori di basket. Med. Sport 2003; 56:317-22. 
Francavilla VC, Genovesi F, Asmundo A, Di Nunno NR, Ambrosi A, Tartaglia N, et al. Fascia andmovement: the primary link in the prevention of accidents in soccer. Revision and models of intervention. Med Sport 2020;73:291-301.

Galli M, Rigoldi C, Mainardi L, Tenore N, Onorati P, Albertini G. Postural control in patients with Down syndrome. Disabil Rehabil. 2008;30(17):1274-8. https://doi.org/10.1080/09638280701610353

Gillespie KM, Dix RJ, Williams AJ, Newton R, Robinson ZF, Bingley PJ, Gale EA, Shield JP. Islet autoimmunity in children with Down's syndrome. Diabetes. 2006;55(11):3185-3188. https://doi.org/10.2337/db06-0856

Hresko MT, McCarthy JC, Goldberg MJ. Hip disease in adults with Down syndrome. J Bone Joint Surg Br.1993;75:604-607. https://doi.org/10.1302/0301-620X.75B4.8331117

Jacobsen FS, Hansson G. Orthopaedic disorders in Down's syndrome. Curr Orthop 2000;14:215-22. https://doi.org/10.1054/cuor.2000.0107

Karlsson B, Gustafsson J, Hedov G, Ivarsson SA, Annerén G. Thyroid dysfunction in Down's syndrome: relation to age and thyroid autoimmunity. Arch Dis Child. 1998;79(3):242-245. https://doi.org/10.1136/adc.79.3.242

Kennedy RL, Jones TH, Cuckle HS. Down's syndrome and the thyroid. Clin Endocrinol (Oxf). 1992;37(6):471-476. https://doi.org/10.1111/j.1365-2265.1992.tb01475.x

Parisi A, Francavilla G, Fusco MA, Buzzanca P, Savojardo M, Francavilla VC. Kinesiology in sport medicine. Immediate diagnostic approach in thermal places.The retical background. Personal experience. La kinesiologia in medicina dello sport. Approccio diagnostico immediato in ambiente termale. Presupposti teorici. Nostre esperienze. Med. Sport 2001;54:325-8.

Perotti LR, Abousamra O., del Pilar Duque Orozco M., Rogers KJ, Sees JP, Miller F. Foot and ankle deformities in children with Down syndrome. J. Child. Orthop. 2018; 12 : 218-226. https://doi.org/10.1302/1863-2548.12.170197

Polito, R., Scarinci, A., Ambrosi, A., Tartaglia, N., Tafuri, D., Monda, M., Messina, A., Cimmino, F., Catapano, A., Sessa, F., Di Maio, G., Francavilla, V.C, Messina, G., \& Monda, V. (2020). The beneficial effects of physical activity and weight loss on human colorectal carcinoma cell lines. Journal of Human Sport and Exercise, 15(2proc), S000-S000. https://doi.org/10.14198/ihse.2020.15.Proc2.16

Rachidi M, Lopes C. Mental retardation in down syndrome: from gene dosage imbalance to molecular and cellular mechanisms. Neurosci Res. 2007;59:349-369. https://doi.org/10.1016/i.neures.2007.08.007

Reeves RH, Baxter LL, Richtsmeier JT. Too much of a good thing: mechanisms of gene action in down syndrome. Trends Gene. 2001;17:83-88. https://doi.org/10.1016/S0168-9525(00)02172-7

Roche E, Hoey H, Dsmig MJ. Medical Management of Children \& Adolescents with Down Syndrome in Ireland, 2015.

Van Goor JC, Massa GG, Hirasing R. Increased incidence and prevalence of diabetes mellitus in Down's syndrome. Arch Dis Child. 1997;77(2):186. https://doi.org/10.1136/adc.77.2.183g

Volman MJ, Visser JJ, Lensvelt-Mulders GJ. Functional status in 5 to 7 -year-old children with Down syndrome in relation to motor ability and performance mental ability Disabil. Rehabil. 2007; $29: 25$ 31. https://doi.org/10.1080/09638280600947617

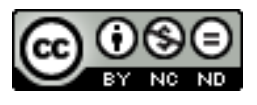

This work is licensed under a Attribution-NonCommercial-NoDerivatives 4.0 International (CC BY-NC-ND 4.0). 